\title{
It's not you, it's me - disgust sensitivity towards body odor in deaf and blind individuals
}

\author{
Michal Mikolaj Stefanczyk ${ }^{1} \cdot$ Anna Oleszkiewicz ${ }^{1,2}$ \\ Published online: 11 June 2020 \\ (C) The Psychonomic Society, Inc. 2020
}

\begin{abstract}
Disgust might be elicited by various sensory channels, including the sense of smell. It has been previously demonstrated that unpleasant odors emitted by an external source are more disgusting than those emitted by oneself (the source effect). As disgust's main purpose is to help organisms avoid potentially dangerous, contaminating objects, individuals with visual or hearing sensory impairment (thus, with an impeded ability to detect cues indicating pathogen threat) might have developed an increased levels of olfactory disgust sensitivity (modality compensation in disgust sensitivity). We set out to investigate disgust sensitivity in olfaction using the Body Odor Disgust Scale (BODS) on a large sample of 74 deaf and 98 blind participants, with comparison to control groups without sensory impairment ( $N=199$ in total). The results did not support the hypothesis of modality compensation in disgust sensitivity. Contrary to previous research, neither sex nor age influenced the outcomes. Evidence for the source effect was found. Acquired data are interpreted in the light of social desirability. The emphasis put on the olfaction by blind and deaf individuals is discussed.
\end{abstract}

Keywords Disgust $\cdot$ Disgust sensitivity $\cdot$ Olfaction $\cdot$ Deaf $\cdot$ Blind

\section{Introduction}

Disgust as one of the basic, universal emotions (Ekman, 1992) serves a vital purpose of avoiding potentially dangerous stimuli (Miller, 2013). Although initially thought to be responsible for the reaction of revulsion towards oral incorporation of inedible or poisonous objects (Davey, 1994; Marzillier \& Davey, 2004; Rozin \& Fallon, 1987), in the course of subsequent research it was found that disgust also encompasses a broader range of elicitors (Kelly, 2011). Disgust may emerge in response to various objects or behaviors, such as germs and disease (Curtis, 2007), body waste (Angyal, 1941; Haidt, Rozin, McCauley, \& Imada, 1997), bad tastes (Rozin, Haidt, \& McCauley, 2008), moistness (Oum, Lieberman, \&

Electronic supplementary material The online version of this article (https://doi.org/10.3758/s13414-020-02075-2) contains supplementary material, which is available to authorized users.

Michal Mikolaj Stefanczyk

michal.m.stefanczyk@gmail.com

1 Institute of Psychology, University of Wroclaw, ul. Dawida 1, 50-527 Wroclaw, Poland

2 Taste and Smell Clinic, Department of Otorhinolaryngology, Technische Universität Dresden, Dresden, Germany
Aylward, 2011) insects, blood (Tybur, Lieberman, \& Griskevicius, 2009), or bad smells (Case, Repacholi, \& Stevenson, 2006; Miller, 1998; Schnall, Haidt, Clore, \& Jordan, 2008), suggesting the multimodal character of disgust.

Mark Schaller $(2006,2015)$ points to the Behavioral Immune System (BIS) as a mechanism that activates the reaction of disgust for the purpose of contamination avoidance. Its main role is to detect pathogen cues and activate adequate emotional and cognitive reactions, and set in motion behaviors that facilitate avoiding pathogen elicitors (Schaller \& Park, 2011). Among the most powerful BIS triggers are potentially contaminating substances, such as body excretions (Curtis, Aunger, \& Rabie, 2004). BIS is mediated by disgust sensitivity (Stevenson, Case, \& Oaten, 2009), a trait responsible for acknowledging certain objects as being repulsive. Both BIS reactivity and disgust sensitivity vary significantly across individuals, depending on both personal features, such as sex or state of pregnancy, and the source of disgust, for instance with different senses being more prone to disgust than others (the senses crucial to disgust, according to various authors, are as follows: touch and smell - Miller, 1998; taste - Rozin et al., 2008; smell, taste, and touch - Miller, 2013; taste, smell, but also touch and vision - Darwin, 1872; touch and taste - Bjorklund \& Hursti, 2004; importance of vision - Curtis et al., 2004; smell, taste, and their transfer to vision Kosmeyer, 2016). 
Darwin (1872) first acknowledged disgust as a fundamental human emotion, but also pointed to various sensory channels through which disgust can be elicited. To date one can find evidence showing disgust elicitation via all five senses, i.e., smell (Bubandt, 1998; Heining, Young, Ioannou, et al., 2003; Wicker et al., 2003), sight (Caseras et al., 2007), touch (e.g., Oum et al., 2011; Saluja \& Stevenson, 2019), taste (DeSimone, Lyall, Heck, \& Feldman, 2001; Eskine, Kacinik, \& Prinz, 2011), and hearing (Croy et al., 2013). The modalities of hearing, seeing, and smelling are distal senses; thus, they constitute the organism's first line of defense against disgust elicitors, namely by keeping distance from potentially threatening stimuli. On the other hand, taste and touch are proximal senses that can warn us that a direct, physical contact with a disgusting object has already taken place and our body should immediately expel the object or break contact with it (Charash \& McKay, 2002; Stevenson, Case, Oaten, Stafford, \& Saluja, 2019).

Various authors reflect on the importance of particular senses to disgust. Most of them agree that taste is the primal detector of repulsiveness (Darwin, 1872; Rozin \& Fallon, 1987; Chapman, Kim, Susskind, \& Anderson, 2009), but touch and smell are considered crucial as well (Miller, 2013), with the latter being strongly connected to taste (Buck \& Bargmann, 2000; Darwin, 1872; Rozin, 1982). Of the three senses mentioned above, only smell is a distal one. Stevenson (2011) indicates that olfactory skills are useful in detecting contamination threats, and as such serve as a disgust-defense mechanism, as part of BIS. Recent studies show that unlike many other emotions, disgust can be easily elicited merely by the sense of smell (Bensafi et al., 2002; Croy, Olgun, \& Jorashky, 2011). These findings suggest the existence of a significant link between disgust sensitivity/BIS and olfaction, a link that has not been extensively explored.

When it comes to research on disgust, theoretical models and recent experimental studies indicate that the feeling of disgust is subject to a few rules, one of which is the "I'm okay, you're not okay" principle (Herz, 2012). It states that the elicitors of disgust are less revolting when we (or the things that we have internalized as "ours") are the source, in comparison to disgust elicitors originated from others (Herz, 2012). This so-called source effect is seen, for instance, with regard to revolting behaviors of a stranger that are perceived as being more disgusting than those of a friend (Peng, Chang, \& Zhou, 2013); in finding one's own dog's excrements less unpleasant than the excrements of somebody else's dog (Stevenson, \& Repacholi, 2005); or preferring the smell of our baby's diaper over the diaper of a stranger baby (Case et al., 2006). The source effect has been taken into account in the Body Odor Disgust Scale (BODS; Liuzza et al., 2017), which consists of two subscales: internal (self) and external (others) body odor sources.
An enhanced olfactory disgust sensitivity as part of BIS might be desirable in the case of visual or hearing impairment. In such situations the role of smell as a means of gathering information about surroundings should increase, since additional information that would normally be gathered though vision or audition is not available. The assumption that the impaired ability to perceive a threatening stimulus with one of the proximal senses may increase the importance of information received through another modality is called a "sensory compensation" (Hoover, Harris, \& Steeves, 2012; Kupers \& Ptito, 2014; Rabinowith \& Bai, 2016). However, to date research concerning sensory compensation has yielded mixed results. While some studies confirmed higher performance of the intact senses among sensory-impaired individuals (Cohen et al., 1997; Hartman \& Abrahams, 2000; Hoover et al., 2012; Lomber, Meredith, \& Kral, 2010; Ptito, Moesgaard, Gjedde, \& Kupers, 2005; Rombaux et al., 2010), others failed to confirm an enhanced sensory performance of people with a sensory loss in comparison to fully functional groups (Guducu, Oniz, Ikiz, \& Ozgoren, 2016; Cornell Kärnekull, Arshamian, Nilsson, \& Larsson, 2016; Majchrzak, Eberhard, Kalaus, \& Wagner, 2017; Smith, Doty, Burlingame, \& McKeown, 1993; Sorokowska, 2016; Sorokowska et al., 2019). None of these studies concerned body odor disgust sensitivity as an olfactory marker of general disgust sensitivity vital to the protection against environmental hazards in people whose sensory defense system has been compromised by either visual or auditory loss. Moreover, some of the previously mentioned research had insufficient numbers of participants (Cox et al., 2002; Cuevas et al., 2010; Dormal, Crollen, Baumans, Lepore, \& Collignon, 2016; Jiang, Stecker, Boynton, \& Fine, 2016; Petitto et al., 2000), making the conclusions weak and thus likely to produce a type II error of false-negative conclusions.

Our aim was to explore the link between visual and auditory loss, and the sensitivity towards disgusting odors elicited by the human body. We expected to observe elevated disgust sensitivity towards body odors as a result of visual and auditory loss. According to our hypothesis, being deprived of one of the proximal senses (vision or audition) results in greater sensitivity to potentially contaminating odors. We expected greater disgust sensitivity towards unpleasant smells in people with visual or hearing impairment. To this end we conducted a study on a large sample of deaf and blind people. The choice of these two particular senses depended on the type of the modality the senses that do not require direct, physical contact with an object are sight, smell, and hearing, thus the feature that is shared by both blind people and deaf people is that they rely on a narrower set of distal senses, including the sense of smell. 


\section{Materials and methods}

\section{Ethics statement}

This study was approved by the ethical board of the Institute of Psychology, University of Wroclaw, and all procedures performed in it involving human participants were in accordance with the ethical standards of the institutional and/or national research committee and with the 1964 Helsinki Declaration and its later amendments or comparable ethical standards. Informed consent was obtained from all individual participants included in the study; the consent form was read aloud to the blind subjects.

\section{Participants}

We estimated the optimal sample size using $G^{*}$ Power Software ((Faul, Erdfelder, Lang, \& Buchner, 2007). Within the repeated-measures analysis of variance (described in detail in the Statistical analyses section) with eight groups (group*sensory impairment*sex), to obtain power of .80 with alpha level set to .05 to detect a small to medium effect of $\mathrm{f} 2=.15$ (Sorokowska, Sorokowski, Karwowski, Larsson, \& Hummel, 2018), the projected sample size was at least 168 subjects. Our sample comprised two main subgroups based on the type of sensory impairment - blind participants $(N=98)$ and deaf participants $(N=74)$. For each of the subgroups we recruited a control group, consisting of sighted individuals $(N=$ 99 ) and hearing individuals $(N=100)$, which we aimed to match in terms of sex and age. Results of these between-group comparisons are summarized in Table 1 . Due to the fact that blind subjects were significantly older than sighted controls, and previous studies indicate that older people are less disgust-sensitive (Fessler \& Navarrete, 2003; Quigley, Sherman, and Sherman, 1997), it was concluded that controlling for age was necessary in the current study.

Table 1. Between-group comparisons of sex distribution, age, and socioeconomic status (SES)

\begin{tabular}{llllllll}
\hline & Sex & $n$ & $\begin{array}{l}\text { Age, } \\
\text { M } \pm \text { SD }\end{array}$ & $\chi^{2}(d f)$ & $p$ & $t(d f)$ & $P$ \\
\hline \multirow{2}{*}{ Deaf } & Women & 36 & $30.7 \pm 11.5$ & $.322(1)$ & .57 & $-.22(172)$ & .83 \\
& Men & 38 & & & & & \\
Hearing & Women & 53 & $31.1 \pm 11.6$ & & & & \\
& Men & 47 & & & & & \\
Blind & Women & 45 & $36.6 \pm 10.1$ & $1.14(1)$ & .285 & $3.32(195)$ & .001 \\
& Men & 53 & & & & & \\
\multirow{2}{*}{ Sighted } & Women & 53 & $31.8 \pm 10.1$ & & & & \\
& Men & 46 & & & & & \\
\hline
\end{tabular}

\section{Procedure}

Participants were examined during individual sessions and were accompanied by the trained research assistant. In the blind group and in the controls-to-blind group, the questionnaire was read out loud by the assistant, whereas both the deaf group and the controls-to-deaf group filled the questionnaire on their own. At the start, the medical interview results were collected to determine any possible factors that could confound their sense of smell or general cognitive abilities (i.e., medical history of sensory loss examinations, head trauma, infections, smoking, pregnancy, etc.; Welge-Luessen, Leopold, \& Miwa, 2013). The standardized interview was supplemented with a single question examining socioeconomic status (SES) utilizing a Likert-type scale ranging from 1 "We live very poorly, we cannot afford basic needs" to 5 "We live very well, we can afford some luxury." Profound deafness was confirmed at two stages. First, study recruitment procedures highlighted that deaf subjects should exhibit a hearing threshold of $>90 \mathrm{~dB}$ (Institute for Quality and Efficiency in Health Care, 2017), but when subjects were not able to present medical documentation of their level of deafness (i.e., an audiogram report), we performed speech audiometry and the triplet test. In the speech audiometry test the participant listens to a monosyllabic target word and selects that word from a group of six phonetically similar words (Hoppe, Hast, \& Hocke, 2015). The triplet test is a hearing task wherein a digit stimulus is used. The participant listens to digit triplets (e.g., 2-6-3), which are presented alongside an interfering noise and selects digits that have been heard (Smits, Kapteyn, \& Houtgast, 2004). These two hearing tests are considered reliable screening tools in auditory assessment, and provide a more accurate overview of an individual's hearing abilities than pure-tone audiometry (Hoppe et al., 2015; Ozimek, Kutzner, Sęk, \& Wicher, 2009; Smits et al., 2004). Both tests were conducted on a PC via a Web-based platform, which is a reliable method of auditory assessment for screening purposes (Masalski, Grysiński, \& Kręcicki, 2014; Masalski \& Krecicki, 2013). Only subjects who had not exceeded $50 \%$ of speech comprehension with their hearing implants on were included in this study. As a result, our deaf sample size was reduced from 103 participants claiming to meet the requirements of the procedure to 74 whose tests had shown a sufficient score to be included in the deaf group. The remaining 29 participants were removed from all statistical analyses.

To determine the level of individual disgust towards unpleasant smells, we asked our participants to complete the BODS (Liuzza et al., 2017). This questionnaire consists of 12 items to which respondents answer using a Likert-type scale, with answers ranging from 1 - "It doesn't disgust me at all" to 5 - "It seriously disgusts me." The BODS consists of two subscales, internal and external body odor sources, 
meaning that the odors might emanate from oneself or from others. All 12 items make up six pairs of similar sentences (concerning the same kind of body odor) that differ only in the source of the smell (for instance, "You are alone at home and notice that your feet smell strongly" (internal subscale) vs. "You are sitting next to a stranger and notice that their feet smell strongly" (external subscale); Liuzza et al., 2017).

\section{Statistical analyses}

All analyses were performed in Jamovi, version 1.0.4.0. (https://www.jamovi.org). To verify whether the groups of sensory-impaired individuals and fully functional controls differed in disgust sensitivity, we examined a repeated-measures analysis of variance (rm-ANCOVA) model with BODS subscales (internal vs. external) as within-subject factors. Due to the difference in giving instructions (blind people and their controls were read instructions out loud while deaf people and their controls received written instructions or were assisted with a sign language translator), we included group (blindness vs. deafness), sensory impairment (yes vs. no), and sex (male vs. female) as independent variables and participants' age as a covariate. Previous research has found that the BODS does not correlate with age (Liuzza et al., 2017). However, both olfactory abilities and disgust sensitivity decline with age (Curtis, Aunger, \& Rabie, 2004; Larsson, Finkel, \& Pedersen, 2000). With regard to participants' sex, studies have shown that women have a more sensitive sense of smell and are more sensitive to disgusting stimuli (Al-Shawaf, Lewis, Alley, \& Buss, 2015; Ship \& Weiffenbach, 1993). In BODS, similar results have been reported, with women scoring higher than men in sensitivity to disgusting smells (Liuzza et al., 2017). Thus, we decided to control for both age and sex in our study. In the Results section we report estimated marginal means for the significant effect followed by $95 \%$ confidence intervals (CIs). At the end of the Results section we present additional Bayesian analysis of the tested repeated-measures ANOVA model.

\section{Results}

The tested model revealed a significant main effect of BODS subscale, $F(1,362)=38.01, p<.001, \eta_{p}^{2}=.10$, suggesting that unpleasant body odors of external source were rated as significantly more disgusting $(\mathrm{M}=4.09 \pm .04[4.02 ; 4.2])$ as compared to self-emitted unpleasant body odors $(\mathrm{M}=3.37 \pm .05$ $[3.27 ; 3.46]$ ), irrespective of group or sensory status of the participants. Furthermore, we noted a significant main effect of sensory impairment, $F(1,362)=4.04, p=.045, \eta_{p}^{2}=.01$, wherein sensory-impaired subjects (both blind and deaf) presented generally higher disgust sensitivity $(\mathrm{M}=3.81 \pm .06$ $[3.70 ; 3.92])$ than their controls $(\mathrm{M}=3.65 \pm .05[3.55$;
3.76]). We found a significant interaction effect between BODS subscale and sensory impairment, $F(1,362)=21.77$, $p<.001, \eta_{\mathrm{p}}^{2}=.06$, wherein a higher level of disgust towards internal body odors was presented by the sensory-impaired individuals ( $\mathrm{M}=3.54 \pm .07[3.40 ; 3.68])$ as compared to their fully functional controls $(\mathrm{M}=3.20 \pm .07[3.07 ; 3.33])$, but this difference was not observed with regard to external source of unpleasant body odors (mean absolute difference between the two groups $(\mathrm{M}=0.03 \pm .08[-.18 ; .12])$ (see Fig. 1). Furthermore, we noted a significant main effect of group, $F(1,362)=4.47, p=.035, \eta_{\mathrm{p}}^{2}=.01$, with higher levels of body odor disgust shown by the "deaf" group (deaf individuals and their controls $)(\mathrm{M}=3.81 \pm .05[3.71 ; 3.92])$ as compared to the "blind" group (blind individuals and their controls) $(\mathrm{M}=3.65$ $\pm .06[3.54 ; 3.76])$, which we further discuss as resulting from the procedure of reading questions out loud to the "blind" group, in contrast to the "deaf" group, who mainly self-read questions. Sex and age factors yielded no significant main or interaction effects $(F<1.45, p>.23 ; F<2.83, p>.09$ respectively; for exact coefficients, see Table 2 ).

Bayesian analysis further corroborated our findings, showing strong support for the model including main effects of BODS scale and sensory impairment and their interaction as compared to the null model with age and subject, $\mathrm{BF}_{10}=3.14^{*} 10^{\wedge} 53$. Bayesian analysis coefficients for all models are presented in the Electronic Supplementary Material.

\section{Discussion}

Results of the present study suggest that unpleasant body odors emitted by others are significantly more disgusting than self-emitted unpleasant body odors. Unpleasant body odors of external source are similarly disgusting to blind and sighted subjects and deaf and hearing individuals, as opposed to the unpleasant body odors of internal source, which seem to be more aggravating to blind and deaf individuals as compared to their controls. Higher disgust sensitivity towards internal body odors was observed in sensory-impaired subjects, thus providing support for our main hypothesis that there is modality compensation concerning disgust sensitivity. However, the analysis of external subscale, which is more crucial for our hypothesis due to the source effect (Stevenson \& Repacholi, 2005), revealed similar levels of disgust between sensoryimpaired and control subjects. This suggests that the "I'm ok, you're not ok" rule overrides the sensory compensation effect. Expected effects of age and sex on disgust sensitivity were not found. Finally, the main effect of group suggests that BODS questions are of a delicate nature and may be subjected to the social desirability bias in such a way that reading scale items out loud to the subjects in assisting the experimenter 


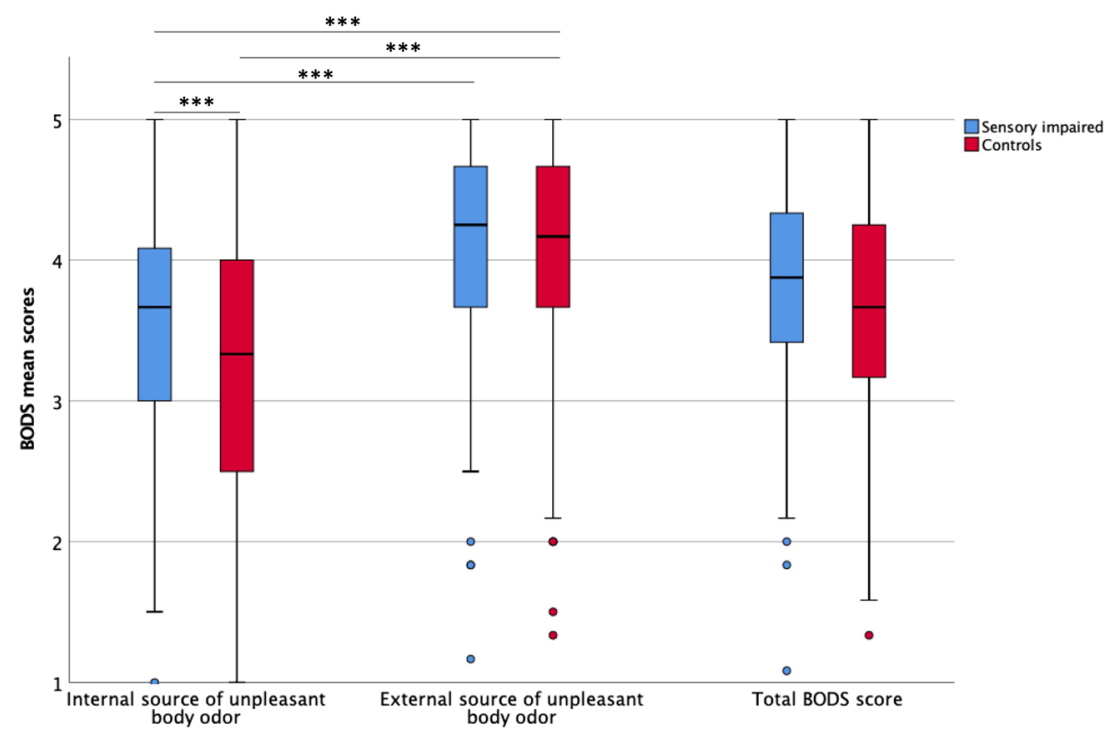

Fig. 1 Interaction effect between the location of the source of unpleasant body odor and sensory impairment (blindness, deafness). Right panel The mean total Body Odor Disgust Scale (BODS) scores that were not

included in the statistical model. Possible scores range from 1 to 5 . The horizonal lines within the bars denote median score

may elicit higher disgust scores as compared to the self-report questionnaires filled in individually.

The results from the internal subscale of BODS suggest that sensory impairment may increase the level of disgust with own body odor smell. Thus, sensory loss may result in a greater awareness of one's smell, perhaps in a way to compensate lack of other sensory-related cues concerning selfpresentation in the social environment. Fully functional

Table 2 The exact statistical coefficients for the tested model

\begin{tabular}{|c|c|c|c|c|c|c|}
\hline & Type III sum of squares & df & Mean square & $\mathrm{F}$ & Sig. & Partial Eta squared \\
\hline \multicolumn{7}{|l|}{ Between-subjects effects } \\
\hline Intercept & 904.76 & 1 & 904.76 & 830.1 & $<.01$ & .70 \\
\hline Age & 3.08 & 1 & 3.08 & 2.83 & .09 & .01 \\
\hline Group & 4.87 & 1 & 4.87 & 4.47 & .035 & .01 \\
\hline Sensory impairment & 4.40 & 1 & 4.40 & 4.04 & .045 & .01 \\
\hline Sex & 1.25 & 1 & 1.25 & 1.15 & .28 & $<.01$ \\
\hline Group * Sensory impairment & 1.24 & 1 & 1.24 & 1.14 & .29 & $<.01$ \\
\hline Group * Sex & .12 & 1 & .12 & .11 & .74 & $<.01$ \\
\hline Sensory impairment $*$ Sex & .06 & 1 & .06 & .06 & .81 & $<.01$ \\
\hline Group $*$ Sensory impairment $*$ Sex & .95 & 1 & .95 & .87 & .35 & $<.01$ \\
\hline Error & 394.54 & 362 & 1.09 & & & \\
\hline \multicolumn{7}{|l|}{ Within-subjects effects } \\
\hline BODS subscale & 10.98 & 1 & 10.98 & 38.01 & $<.01$ & .10 \\
\hline BODS subscale * Age & .06 & 1 & .06 & .22 & .64 & $<.01$ \\
\hline BODS subscale * Group & .02 & 1 & .02 & .07 & .80 & $<.01$ \\
\hline BODS subscale * Sensory impairment & 6.29 & 1 & 6.29 & 21.77 & $<.001$ & .06 \\
\hline BODS subscale $*$ Sex & .42 & 1 & .42 & 1.44 & .23 & $<.01$ \\
\hline BODS subscale * Group * Sensory impairment & .27 & 1 & .27 & .92 & .34 & $<.01$ \\
\hline BODS subscale * Group $*$ Sex & .46 & 1 & .46 & 1.59 & .21 & $<.01$ \\
\hline BODS subscale $*$ Sensory impairment $*$ Sex & .25 & 1 & .25 & .88 & .35 & $<.01$ \\
\hline BODS subscale * Group * Sensory impairment * Sex & .19 & 1 & .19 & .64 & .42 & $<.01$ \\
\hline Error (BODS subscale) & 104.58 & 362 & 0.29 & & & \\
\hline
\end{tabular}

BODS Body Odor Disgust Scale 
individuals can regulate the way they present themselves using all three distal senses - vision, audition, and in terms of smell, whereas sensory-impaired individuals rely on just two of the three distal senses, thus those two senses may play a greater role in their self-presentation. Blind and deaf subjects in our study present a lower disgust threshold to their own body odor. Being more prone to odorous cues of one's own body may relate to the human chemosensory communication. Blind and deaf subjects may present more concern about their body odor as a subject of potential social judgement. This might be one of the many issues for blind and deaf people in everyday preparation for entering social experiences that non-impaired individuals simply underestimate (Thomas, 2004a, b). Because BODS does not allow examination of the perspective of social concern in relation to body odor emitted by the respondents, this speculation calls for further investigation. Another possible explanation of the increased disgust with own body odor in sensoryimpaired subjects may refer to the generally elevated selfassessed sensory sensitivity (Pieniak, Lachowicz-Tabaczek, Masalski, Hummel, \& Oleszkiewicz, 2020), which may lead to increased admission of unpleasant experiences with malodor, including those emitted by the human body.

The results of the external subscale of BODS implies that the hypothesis of sensory compensation in disgust sensitivity is only partially supported by the extent of internal body odors, and does not apply to external sources of disgusting smell emitted by the human body. We expected to observe pronounced differences between sensory-impaired subjects and their control groups because in accordance with the source effect the disgust elicited by others should be more repulsive and threatening than disgust elicited by oneself (Stevenson \& Repacholi, 2005). Results of the current study do confirm that the source effect is applicable to the groups of visually and auditory impaired subjects. Observed results of the external source of unpleasant body odor subscale are notably high, suggesting that the reported interaction between BODS subscale and sensory impairment might be a byproduct of the ceiling effect in this subscale. This speculation calls for the development of more subtle measurement of external sources of body odor disgust, possibly supplemented with psychophysical and electrophysiological approaches to introduce more variance to the data and better differentiate subjects.

The effect of group on external BODS subscale may result from social desirability bias (Paulhus \& Trapnell, 2008). The "deaf" group (and their controls) completed the questionnaire on their own and enjoyed more privacy doing so than did the "blind" group (and their controls), who had the questionnaire read to them out loud and provided their answers orally. The desire to self-present as less disgusted by human body odor might have been the reason for deflating their declared disgust sensitivity and this should be controlled in future studies.
Concerning statistically insignificant effects of age and sex, the results can be explained from the perspective of the used methodology. However, the effect of disgust sensitivity declining with age is well established and has been reported in many studies (for instance, Curtis et al., 2004; Fessler \& Navarrete, 2005; Quigley et al., 1997). Age is also one of the main predictors of olfactory loss (Hummel, Futschik, Frasnelli, \& Huttenbrink, 2003), which is directly linked to body odor sensitivity. However, our sample was rather young and did not include subjects older than 57 years. It is likely that the sample was too homogenous to observe agerelated effects in body odor disgust sensitivity.

When it comes to participants' sex, null results might seem even more surprising than in previous cases due to the large number of studies showing sex differences in disgust (AlShawaf, Lewis, Alley, \& Buss, 2015; Al-Shawaf, Lewis, \& Buss, 2018; Caseras et al., 2007; Haidt, McCauley, \& Rozin, 1994; Montagne, Kessels, Frigerio, de Haan, \& Perrett, 2005; Olatunji, Sawchuk, Arrindell, \& Lohr, 2005b; Olatunji, Arrindell, \& Lohr, 2005a; Tybur et al., 2009). However, the tool that was applied in the study (BODS) is exceptionally weak in terms of a disgust-sensitivity measuring method in differentiating between the two sexes (Liuzza et al., 2017). Although sex differences in disgust sensitivity might reach over Cohen's $d=1.5$, authors of the BODS questionnaire report a small effect of sex, $d=.18$.

The limitations of the study should be mentioned. Firstly, in studies concerning variables such as disgust sensitivity and modality compensation, the "tails" of a population's age should be included, namely children and the elderly, as those with the weakest immunology (Herz, 2012) or whose experience with modality impairment is especially small/great. The current study consisted of participants aged between 16 and 57 years and did not involve children or older people. Secondly, the study was based on self-reported data and should be supplemented with behavioral data in the future.

Notably, our study provides compelling evidence on the effects of sensory loss on body odor disgust sensitivity due to the sample size - to date, studies including deaf and blind participants were largely underpowered (eight participants in Cuevas et al. 2010; seven individuals in Jiang et al. 2016; ten blind people in Dormal et al. 2016; 11 deaf people in Petitto et al., 2000; or two deaf participants in Cox et al., 2002).

Funding details This work was supported by the Polish National Science Centre (\#2017/25/B/HS6/00561) and the Ministry of Science and Higher Education (\#626/STYP/12/ 2017), both awarded to AO.

\section{Compliance with ethical standards}

Data accessibility statement The authors declare no conflicts of interest. The data that support the findings of this study are available from the corresponding author, MMS, upon reasonable request. 


\section{References}

Al-Shawaf, L., Lewis, D. M., Alley, T. R., \& Buss, D. M. (2015). Mating strategy, disgust, and food neophobia. Appetite, 85, 30-35.

Al-Shawaf, L., Lewis, D. M., \& Buss, D. M. (2018). Sex differences in disgust: Why are women more easily disgusted than men?. Emotion review, 10(2), 149-160.

Angyal, A. (1941). Disgust and related aversions. The Journal of Abnormal and Social Psychology, 36(3), 393.

Bensafi, M., Rouby, C., Farget, V., Bertrand, B., Vigouroux, M., \& Holley, A. (2002). Autonomic nervous system responses to odours: the role of pleasantness and arousal. Chemical Senses, 27(8), 703709.

Björklund, F., \& Hursti, T. J. (2004). A Swedish translation and validation of the Disgust Scale: A measure of disgust sensitivity. Scandinavian Journal of Psychology, 45(4), 279-284.

Bubandt, N. (1998). The Odour of Things: Smell and the Cultural Elaboration of Disgust in Eastern Indonesia. Ethnos, 63(1), 48-80.

Buck, L. B., \& Bargmann, C. (2000). Smell and taste: The chemical senses. Principles of neural science, 4, 625-647.

Case, T. I., Repacholi, B. M., \& Stevenson, R. J. (2006). My baby doesn't smell as bad as yours: The plasticity of disgust. Evolution and Human Behavior, 27(5), 357-365.

Caseras, X., Mataix-Cols, D., An, S. K., Lawrence, N. S., Speckens, A., Giampietro, V., ... Phillips, M. L. (2007). Sex differences in neural responses to disgusting visual stimuli: implications for disgustrelated psychiatric disorders. Biological Psychiatry, 62(5), 464-471.

Chapman, H. A., Kim, D. A., Susskind, J. M., \& Anderson, A. K. (2009). In bad taste: Evidence for the oral origins of moral disgust. Science, 323(5918), 1222-1226.

Charash, M., \& McKay, D. (2002). Attention bias for disgust. Journal of anxiety disorders, 16(5), 529-541.

Cohen, L. G., Celnik, P., Pascual-Leone, A., Corwell, B., Faiz, L., Dambrosia, J., ... Hallett, M. (1997). Functional relevance of cross-modal plasticity in blind humans. Nature, 389(6647), 180.

Cornell Kärnekull, S., Arshamian, A., Nilsson, M. E., \& Larsson, M. (2016). From perception to metacognition: auditory and olfactory functions in early blind, late blind, and sighted individuals. Frontiers in psychology, 7, 1450.

Cox, S., Lincoln, M., Tryggvason, J., Nakisa, M., Wells, M., Tutt, M., \& Abbott, S. (2002). Tessa, a system to aid communication with deaf people. In Proceedings of the fifth international ACM conference on Assistive technologies (pp. 205-212). ACM.

Croy, I., Olgun, S., \& Joraschky, P. (2011). Basic emotions elicited by odours and pictures. Emotion, 11(6), 1331.

Croy, I., Laqua, K., Süß, F., Joraschky, P., Ziemssen, T., \& Hummel, T. (2013). The sensory channel of presentation alters subjective ratings and autonomic responses toward disgusting stimuli-Blood pressure, heart rate and skin conductance in response to visual, auditory, haptic and olfactory presented disgusting stimuli. Frontiers in Human Neuroscience, 7, 510.

Cuevas, I., Plaza, P., Rombaux, P., Collignon, O., De Volder, A. G., \& Renier, L. (2010). Do people who became blind early in life develop a better sense of smell? A psychophysical study. Journal of Visual Impairment \& Blindness, 104(6), 369-379.

Curtis, V., Aunger, R., \& Rabie, T. (2004). Evidence that disgust evolved to protect from risk of disease. Proceedings of the Royal Society of London. Series B: Biological Sciences 271(suppl_4), S131-S133.

Curtis, V. A. (2007). Dirt, disgust and disease: a natural history of hygiene. Journal of Epidemiology \& Community Health, 61(8), 660-664.

Darwin, C. (1872). The expression of emotions in animals and man. London: Murray.

Davey, G. C. L. (1994). Self-reported fears to common indigenous animals in an adult UK population: The role of disgust sensitivity. British Journal of Psychology, 85(4), 541-554.
DeSimone, J. A., Lyall, V., Heck, G. L., \& Feldman, G. M. (2001). Acid detection by taste receptor cells. Respiration physiology, 129(1-2), 231-245.

Dormal, V., Crollen, V., Baumans, C., Lepore, F., \& Collignon, O. (2016). Early but not late blindness leads to enhanced arithmetic and working memory abilities. Cortex, $83,212-221$.

Ekman, P. (1992). Are There Basic Emotions? Psychological Review, 99(3), 550-553.

Eskine, K. J., Kacinik, N. A., \& Prinz, J. J. (2011). A bad taste in the mouth: Gustatory disgust influences moral judgment. Psychological Science, 22(3), 295-299.

Faul, F., Erdfelder, E., Lang, A.-G., \& Buchner, A. (2007). G*Power 3: A flexible statistical power analysis program for the social, behavioral, and biomedical sciences. Behavior Research Methods, 39(2), 175-191.

Fessler, D. M., \& Navarrete, C. D. (2003). Domain-specific variation in disgust sensitivity across the menstrual cycle. Evolution and Human Behavior, 24(6), 406-417.

Fessler, D. M., \& Navarrete, C. D. (2005). The effect of age on death disgust: Challenges to terror management perspectives. Evolutionary Psychology, 3(1).

Guducu, C., Oniz, A., Ikiz, A. O., \& Ozgoren, M. (2016). Chemosensory function in congenitally blind or deaf teenagers. Chemosensory Perception, 9(1), 8-13.

Haidt, J., McCauley, C., \& Rozin, P. (1994). Individual differences in sensitivity to disgust: A scale sampling seven domains of disgust elicitors. Personality and Individual differences, 16(5), 701-713.

Haidt, J., Rozin, P., McCauley, C., \& Imada, S. (1997). Body, psyche, and culture: The relationship between disgust and morality. Psychology and Developing Societies, 9(1), 107-131.

Hartman, E. J., \& Abrahams, M. V. (2000). Sensory compensation and the detection of predators: the interaction between chemical and visual information. Proceedings of the Royal Society of London. Series B: Biological Sciences, 267(1443), 571-575.

Heining, M., Young, A. W., Ioannou, G., Andrew, C. M., Brammer, M. J., Gray, J. A., \& Phillips, M. L. (2003). Disgusting smells activate human anterior insula and ventral striatum. Annals of the New York Academy of Sciences, 1000(1), 380-384.

Herz, R. (2012). That's disgusting: Unraveling the mysteries of repulsion. WW Norton \& Company

Hoover, A. E., Harris, L. R., \& Steeves, J. K. (2012). Sensory compensation in sound localization in people with one eye. Experimental brain research, 216(4), 565-574.

Hoppe, U., Hast, A., \& Hocke, T. (2015). Audiometry-Based Screening Procedure for Cochlear Implant Candidacy. Otology \& Neurotology, 36(6), 1001-1005.

Hummel, T., Futschik, T., Frasnelli, J., \& Hüttenbrink, K. B. (2003). Effects of olfactory function, age, and gender on trigeminally mediated sensations: a study based on the lateralization of chemosensory stimuli. Toxicology letters, 140, 273-280.

Institute for Quality and Efficiency in Health Care. (2017). Hearing loss and deafness: Normal hearing and impaired hearing. Retrieved from https://www.ncbi.nlm.nih.gov

Jiang, F., Stecker, G. C., Boynton, G. M., \& Fine, I. (2016). Early blindness results in developmental plasticity for auditory motion processing within auditory and occipital cortex. Frontiers in human neuroscience, $10,324$.

Kelly, D. (2011). Yuck!: the nature and moral significance of disgust. MIT press.

Kosmeyer, C. (2016). Disgust. Filozofski vestnik, 20(2).

Kupers, R., \& Ptito, M. (2014). Compensatory plasticity and cross-modal reorganization following early visual deprivation. Neuroscience \& Biobehavioral Reviews, 41, 36-52.

Larsson, M., Finkel, D., \& Pedersen, N. L. (2000). Odor identification: influences of age, gender, cognition, and personality. The Journals of Gerontology Series B: Psychological Sciences and Social Sciences, 55(5), P304-P310. 
Liuzza, M. T., Lindholm, T., Hawley, C., Sendén, M. G., Ekström, I., Olsson, M. J., ... Olofsson, J. K. (2017). The body odour disgust scale (BODS): development and validation of a novel olfactory disgust assessment. Chemical senses, 42(6), 499-508.

Lomber, S. G., Meredith, M. A., \& Kral, A. (2010). Cross-modal plasticity in specific auditory cortices underlies visual compensations in the deaf. Nature neuroscience, 13(11), 1421.

Majchrzak, D., Eberhard, J., Kalaus, B., \& Wagner, K. H. (2017). Do visually impaired people develop superior smell ability? Perception, 46(10), 1171-1182.

Marzillier, S. L., \& Davey, G. C. L. (2004). The emotional profiling of disgust-eliciting stimuli: Evidence for primary and complex disgusts. Cognition and Emotion, 18(3), 313-336.

Masalski, M., \& Krecicki, T. (2013). Self-test web-based pure-tone audiometry: Validity evaluation and measurement error analysis. Journal of Medical Internet Research, 15(4).

Masalski, M., Grysiński, T., \& Kręcicki, T. (2014). Biological calibration for web-based hearing tests: evaluation of the methods. Journal of Medical Internet Research, 16(1).

Miller, S. (2013). Disgust: The gatekeeper emotion. Routledge.

Miller, W. I. (1998). The anatomy of disgust. Harvard University Press.

Montagne, B., Kessels, R. P., Frigerio, E., de Haan, E. H., \& Perrett, D. I. (2005). Sex differences in the perception of affective facial expressions: Do men really lack emotional sensitivity?. Cognitive processing, 6(2), 136-141.

Olatunji, B. O., Arrindell, W. A., \& Lohr, J. M. (2005a). Can the sex differences in disgust sensitivity account for the sex differences in blood-injection-injury fears?. Personality and Individual Differences, 39(1), 61-71.

Olatunji, B. O., Sawchuk, C. N., Arrindell, W. A., \& Lohr, J. M. (2005b). Disgust sensitivity as a mediator of the sex differences in contamination fears. Personality and Individual Differences, 38(3), 713-722.

Oum, R. E., Lieberman, D., \& Aylward, A. (2011). A feel for disgust: tactile cues to pathogen presence. Cognition and Emotion, 25(4), 717-725.

Ozimek, E., Kutzner, D., Sęk, A., \& Wicher, A. (2009). Development and evaluation of Polish digit triplet test for auditory screening. Speech Communication, 51(4), 307-316.

Paulhus, D. L., \& Trapnell, P. D. (2008). Self-presentation of personality. Handbook of personality psychology, 19, 492-517.

Peng, M., Chang, L., \& Zhou, R. (2013). Physiological and behavioral responses to strangers compared to friends as a source of disgust. Evolution and Human Behavior, 34, 94-98.

Pieniak, M., Lachowicz-Tabaczek, K., Masalski, M., Hummel, T., \& Oleszkiewicz, A. (2020). Self-rated sensory performance in profoundly deaf individuals. Do deaf people share the conviction about sensory compensation?. Journal of Sensory Studies, e12572.

Petitto, L. A., Zatorre, R. J., Gauna, K., Nikelski, E. J., Dostie, D., \& Evans, A. C. (2000). Speech-like cerebral activity in profoundly deaf people processing signed languages: implications for the neural basis of human language. Proceedings of the National Academy of Sciences, 97(25), 13961-13966.

Ptito, M., Moesgaard, S. M., Gjedde, A., \& Kupers, R. (2005). Crossmodal plasticity revealed by electrotactile stimulation of the tongue in the congenitally blind. Brain, 128(3), 606-614.

Quigley, J. F., Sherman, M. F., \& Sherman, N. C. (1997). Personality disorder symptoms, gender, and age as predictors of adolescent disgust sensitivity. Personality and Individual Differences, 22(5), 661-667.

Rabinowitch, I., \& Bai, J. (2016). The foundations of cross-modal plasticity. Communicative \& integrative biology, 9(2).
Rombaux, P., Huart, C., De Volder, A. G., Cuevas, I., Renier, L., Duprez, T., \& Grandin, C. (2010). Increased olfactory bulb volume and olfactory function in early blind subjects. Neuroreport, 21(17), 1069-1073.

Rozin, P. (1982). Taste-smell confusions and the duality of the olfactory sense. Perception \& psychophysics, 37, 397-401

Rozin, P., \& Fallon, A. E. (1987). A Perspective on Disgust. Psychological Review, 94(1), 23-41.

Rozin, P., Haidt, J., \& McCauley, C. R. (2008). Disgust. In M. Lewis \& J. M. Haviland-Jones (Eds.), Handbook of emotions (2nd, pp. 637653). New York: Guilford Press.

Saluja, S., \& Stevenson, R. (2019). Author accepted manuscript: Perceptual and Cognitive Determinants of Tactile Disgust. Quarterly Journal of Experimental Psychology, 1747021819862500.

Schaller, M. (2006). Parasites, behavioral defenses, and the social psychological mechanisms through which cultures are evoked. Psychological Inquiry, 17(2), 96-101.

Schaller, M. (2015). The behavioral immune system. The Handbook of Evolutionary Psychology, 1-19.

Schaller, M., \& Park, J. H. (2011). The behavioral immune system (and why it matters). Current directions in psychological science, 20(2), 99-103.

Schnall, S., Haidt, J., Clore, G. L., \& Jordan, A. H. (2008). Disgust as embodied moral judgment. Personality and social psychology bulletin, 34(8), 1096-1109.

Ship, J. A., \& Weiffenbach, J. M. (1993). Age, gender, medical treatment, and medication effects on smell identification. Journal of gerontology, 48(1), M26-M32.

Smith, R. S., Doty, R. L., Burlingame, G. K., \& McKeown, D. A. (1993). Smell and taste function in the visually impaired. Perception \& Psychophysics, 54(5), 649-655.

Smits, C., Kapteyn, T. S., \& Houtgast, T. (2004). Development and validation of an automatic speech-in-noise screening test by telephone. International Journal of Audiology, 43(1), 15-28.

Sorokowska, A. (2016). Olfactory performance in a large sample of earlyblind and late-blind individuals. Chemical Senses, 41(8), 703-709.

Sorokowska, A., Sorokowski, P., Karwowski, M., Larsson, M., \& Hummel, T. (2018). Olfactory perception and blindness: a systematic review and meta-analysis. Psychological research, 1-17.

Sorokowska, A., Oleszkiewicz, A., Stefańczyk, M., Płachetka, J., Dudojć, O., Ziembik, K., ... Hummel, T. (2019). Odour lateralization and spatial localization: Null effects of blindness. Attention, Perception, \& Psychophysics, 1-10.

Stevenson, R. J. (2011). Olfactory illusions: Where are they? Consciousness and cognition, 20(4), 1887-1898.

Stevenson, R. J., \& Repacholi, B. M. (2005). Does the source of an interpersonal odour affect disgust? A disease risk model and its alternatives. European Journal of Social Psychology, 35(3), 375-401.

Stevenson, R. J., Case, T. I., \& Oaten, M. J. (2009). Frequency and recency of infection and their relationship with disgust and contamination sensitivity. Evolution and Human Behavior, 30(5), 363-368.

Stevenson, R. J., Case, T. I., Oaten, M. J., Stafford, L., \& Saluja, S. (2019). A Proximal Perspective on Disgust. Emotion Review, 1754073919853355.

The jamovi project (2019). jamovi (Version 0.9) [Computer Software]. Retrieved from https://www.jamovi.org

Thomas, C. (2004a). Disability and impairment. Disabling barriersenabling environments, 2.

Thomas, C. (2004b). Rescuing a social relational understanding of disability. Scandinavian Journal of Disability Research, 6(1), 22-36. 
Tybur, J. M., Lieberman, D., \& Griskevicius, V. (2009). Microbes, mating, and morality: individual differences in three functional domains of disgust. Journal of personality and social psychology, 97(1), 103.

Welge-Luessen, A., Leopold, D., \& Miwa, T. (2013). Smell and taste disorders diagnostic and clinical work-up. In Antje Welge-Luessen $\&$ T. Hummel (Eds.), Management of smell and taste disorders-a practical guide for clinicians (pp. 49-57).
Wicker, B., Keysers, C., Plailly, J., Royet, J. P., Gallese, V., \& Rizzolatti, G. (2003). Both of us disgusted in My insula: the common neural basis of seeing and feeling disgust. Neuron, 40(3), 655-664.

Publisher's note Springer Nature remains neutral with regard to jurisdictional claims in published maps and institutional affiliations. 